\title{
SINCRETISMO E QUESTÃO RACIAL: RELAÇÕES LEXICAIS E REPRESENTAÇÕES CONFLITANTES EM DOIS JORNAIS E DUAS REVISTAS IMPRESSAS BRASILEIRAS*

\begin{abstract}
(Syncretism and the racial issue: lexical relations and conflicting representations in two newspapers and two magazines in Brazil)
\end{abstract}

\author{
Cláudio Márcio do CARMo \\ (UFSJ/UFMG) \\ Célia Maria MagalHães \\ (UFMG-CNPq)
}

\begin{abstract}
Resumo: Na área das Ciências Sociais, em especial a Antropologia, o sincretismo tem comumente sido foco de estudo. $\mathrm{Na}$ área de estudos linguísticos, a pesquisa sobre esse tema é ainda incipiente. Este artigo tem como objetivo contribuir para preencher essa lacuna nos estudos linguísticos, partindo da análise do item lexical sincretismo como culturalmente relevante para o estudo de discursos sobre a questão racial, mediados por veículos de comunicação impressa. Utiliza-se como referencial teórico a Análise Crítica do Discurso e algumas ferramentas da Linguística de Corpus para a análise das relações lexicais estabelecidas com o item sincretismo em dois jornais e duas revistas de informação geral. Alguns dos resultados apontam para um conflito entre diferentes discursos religiosos e uma tensão no discurso da democracia racial brasileira.
\end{abstract}

Palavras-chave: sincretismo; relaçôes lexicais; questão racial; Análise Crítica do Discurso.

Abstract: In the field of Social Sciences, especially Anthropology, syncretism has often been focused on as a research topic. In the field of linguistic studies, there is very little or apparently no research on the issue being carried out in Brazil. This article aims at filling in this gap in linguistic studies. It sets out from an analysis of the lexical item syncretism as culturally relevant for the study of discourses on the racial issue in Brazil, as mediated by the press. The theoretical background of Critical Discourse Analysis and some tools of

\footnotetext{
* Texto baseado na Tese de Doutoramento intitulada Relações lexicais, interdiscursividade e representação: o sincretismo e a questão racial em corpus de jornais e revistas brasileiras, defendida em 2005 na Faculdade de Letras da Universidade Federal de Minas Gerais (FALE/UFMG), sob a orientação da Profa. Dra. Célia Maria Magalhães.
} 
Corpus Linguistics are combined in order to investigate lexical relations constructed with the word sincretismo in two newspapers and two feature magazines. Some of the results suggest there is a conflict between different religious discourses and a tension in the wider discourse of racial democracy in Brazil.

Key-words: syncretism; lexical relations; discourse on race; Critical Discourse Analysis.

\section{INTRODUÇÃO}

Para Valente (1976), o sincretismo como objeto de pesquisa na área das ciências sociais já teria se esgotado, entretanto, o retorno frequente a esse tema em vários contextos institucionais brasileiros contesta esse pensamento, revelando que ainda existem nuances que podem ser trabalhadas por diferentes olhares que visem a um avanço na problematização desse assunto. Do ponto de vista acadêmico, em especial antropológico e social (ver, especialmente, Ferretti, 1995, 2001), o sincretismo nem sempre é visto como positivo, contrariamente, por exemplo, ao ponto de vista de algumas mídias que parecem representá-lo majoritariamente como uma mistura positiva de traços de culturas diferentes.

$\mathrm{Na}$ área de estudos linguísticos, a pesquisa que tem esse tema como foco de estudo é ainda incipiente, muito embora pareça ser frequente a ocorrência do item lexical sincretismo em textos midiáticos, com os quais temos contato diário e os quais parecem ter assumido papel preponderante na construção de crenças e ideologias.

Neste artigo, procurar-se-á explicitar de que maneira a mídia de jornais e revistas de informação geral tem representado o sincretismo - aqui visto como um imbricado processo de transformação - segundo, principalmente, o conceito de interdiscursividade, de acordo com a concepção da Análise Crítica do Discurso.

Intertextualidade e interdiscursividade são categorias que dão corpo ao processo de hibridização - mistura de textos, gêneros discursivos e discursos (cf. Fairclough, 1999) - na produção dos eventos discursivos. Enquanto a intertextualidade mostra a presença de outros textos numa articulação local no texto, a interdiscursividade, de forma mais complexa, estaria presente na imbricação global de gêneros discursivos e discursos, gerando uma rearticulação que pode incidir sobre o discurso em si e sobre o próprio gênero. 
Como explicita Fairclough (2001: 136), o termo intertextualidade foi criado por J. Kristeva retomando o pensamento de Mikhail Bakhtin e se refere à configuração de textos e a proferimentos anteriores. Nas palavras do autor,

Além de incorporar ou, por outro lado, responder a outros textos, a intertextualidade do texto pode ser considerada como incorporando as relações potencialmente complexas que tem com as convenções (gêneros, discursos, estilos, tipos de atividades) que estão estruturadas juntas e constituem uma ordem do discurso.

Por isso,

a intertextualidade manifesta é o caso em que se recorre explicitamente a outros textos específicos em um texto, enquanto a interdiscursividade é uma questão de como um tipo de discurso é constituído por meio de uma combinação de elementos de ordens do discurso (Fairclough, 2001: 152).

Para Locke (2005: 9), "o conceito de intertextualidade se relaciona aos modos como textos recorrem a outros textos em virtude das histórias (ou discursos) neles embutidos" e, para Bloor \& Bloor (2007: 7), intertextualidade é "o modo como um texto conta com textos prévios para sua formação e referências e os modos pelos quais pode incorporar outros textos”. Por isso, Fairclough (2001: 136-137) explica que introduziu e dará preferência ao termo interdiscursividade quando se tratar de convenções discursivas e apenas usará intertextualidade quando textos forem claramente citados no interior de outros.

Tal aparato revela que é possível analisar a linguagem partindo de categorias que dão acesso ao hibridismo discursivo como mecanismo de relação entre discursos e gêneros no interior da sociedade. Esse é o espaço em que a linguística aplicada pode contribuir, mostrando como se realiza a tensão entre os discursos que formam o sincretismo brasileiro e sua possível associação com a questão racial. Com um novo olhar, ela poderá ajudar a problematizar e procurar evidências linguísticas, textuais e discursivas, que possam trazer à tona alguns aspectos da construção de novos posicionamentos sobre as muitas variáveis envolvidas com a noção de sincretismo, através da análise de suas co-ocorrências lexicais e suas correlações intratextuais e discursivas em textos da mídia, já que o discurso midiático tem um papel relevante na reprodução e construção de pensamentos na sociedade. 
A leitura crítica de textos midiáticos impressos pode contribuir para este campo de estudos, pois parece haver uma frequência significativa do item lexical sincretismo, tomado como palavra-chave (Williams, 1976, ver definição do conceito na seção Referencial Teórico) nestes textos. Tal frequência de uso, associada à co-ocorrência com outros itens lexicais, parece reproduzir e/ou construir significados que apontam para um processo de luta e conflito no discurso mediado. Esse conflito parece surgir no início da década de 1980 do século passado, no momento em que um discurso naturalizado do sincretismo como a mistura "perfeita" e idealizada de raças, religiões e culturas, é desafiado por outros discursos os quais entram em luta com o primeiro. Como exemplo, podemos citar os discursos do antissincretismo e o da reafricanização, introduzidos por brasileiros descendentes de africanos, vinculados, em especial, à instituição religiosa do Candomblé, uma das possíveis razões para que o campo mais evocado nos textos quando se menciona o sincretismo seja a religião.

Este artigo está, assim, dividido em seis seções: nas duas primeiras, serão apresentadas breves revisões dos referenciais teóricos das Ciências Sociais e da Análise Crítica do Discurso, utilizados, o primeiro como ponto de partida e o segundo como afiliação teórica para a abordagem do tema; na terceira, uma breve descrição do corpus e dos procedimentos metodológicos utilizados para a sua análise; na quarta e quinta, apresenta-se a análise e discussão dos dados encontrados e, finalmente, na sexta e última apresentase uma tentativa de interpretação dos dados à luz da teoria e metodologia utilizada na análise.

\section{O SinCRETISMO Nas CiênCIAS Sociais}

O sincretismo remonta à época de constituição do Brasil colônia e parece vincular-se a um discurso que tenta explicar e/ou apaziguar a natureza conflituosa da constituição da sociedade brasileira, calcada nas ideologias do branqueamento, da mistura perfeita de religiões e culturas diferentes e no mito da democracia racial.

Conforme já indicado em inúmeros trabalhos sobre História do Brasil (ver, por exemplo, Silva, 1994), o contexto de íntimo contato entre portugueses e africanos, com suas respectivas religiões, culturas e línguas propiciou o surgimento de um processo inter-religioso, intercultural e interlinguístico denominado sincretismo. Deve-se ressalvar que, embora 
esse trabalho tenha se circunscrito ao estudo da relação entre portugueses e africanos, esse fenômeno também se dá em relação aos índios, como se pode ver em Vainfas (1995).

Pierson - citado por Valente (1976: 10) - afirma que sincretismo é um processo que se propõe a resolver uma situação de conflito cultural e se caracteriza pela luta por status. Valente (1976: 11-12) acrescenta que o sincretismo também se caracteriza por uma intermistura de elementos culturais, uma íntima interfusão, uma verdadeira simbiose, em alguns casos, entre os componentes das culturas que se põem em contato.

Em primeira instância, pode-se afirmar que houve uma aparente correspondência estabelecida conscientemente entre os santos cristãos e as divindades do panteão africano. E os efeitos dessa reflexão consciente, aos poucos, foram se automatizando, tornando-se irrefletidos, inconscientes, uma vez que o campo da religiosidade dos próprios africanos e de seus descendentes brasileiros foi-se desenvolvendo em contato estreito com aquele dos portugueses.

Do ponto de vista etimológico, conforme Cunha (1982: 725) esclarece, sincretismo é uma palavra derivada do francês syncrétisme, por sua vez, derivado do latim científico syncretismus que já era derivado do grego sygkretismós. Segundo o autor, essa palavra designava o amálgama de doutrinas ou concepções diferentes e, na Filosofia, designava uma reunião artificial de ideias ou de teses de origens disparatadas.

Esse "disparate", em termos brasileiros, pode ser interpretado em relação aos métodos utilizados para análise dos contatos entre as culturas africanas e europeias: o método comparativista que veio substituir o método histórico.

Com a limitação dos estudos históricos sobre os africanos, a pesquisa etnológica baseada em métodos comparativistas ganha força a partir dos trabalhos do professor Raimundo Nina Rodrigues, estudioso baiano considerado um marco dos estudos sobre os africanos e seus descendentes no Brasil. Após sua morte em 1906, houve uma estagnação na área que durou até 1926 quando o antropólogo Arthur Ramos e, posteriormente, seus discípulos retomam seus escritos e continuam as pesquisas na área. A partir de então, essa retomada ganhou novos rumos, sendo feita também por sociólogos, como Gilberto Freyre, sobretudo, em sua obra Casa grande e senzala. 
Dessa maneira, os estudos sobre os contatos culturais que dariam mais tarde origem ao que se intitularia estudos afro-brasileiros nas Ciências Humanas de modo geral se intensificam e muitas das lacunas encontradas nas obras de Nina Rodrigues são preenchidas.

Segundo Ferretti (2001: 14-15), o termo sincretismo foi rejeitado por muitos pesquisadores, por possuir conotações negativas, pois é considerado impreciso e ambíguo. Diferentemente de Nina Rodrigues, que não o usa, seu discípulo Arthur Ramos - substituindo a perspectiva evolucionista de raça de seu mestre por outra culturalista - retoma o termo sincretismo. No início, Arthur Ramos via o sincretismo como um resultado harmonioso dos contatos culturais, mas posteriormente constata que nem sempre o contato ocorre de maneira harmoniosa, principalmente quando está associado à colonização e à escravidão.

No percurso de estudos sobre o sincretismo, Ferretti (1995, 2001) também destaca os trabalhos dos médicos Ulisses Pernambucano de Mello, Gonçalves Fernandes e Valdemar Valente, e do sociólogo humanista Gilberto Freyre, como sendo pioneiros na publicação de livros acerca do assunto.

Outro nome destacado por Ferretti (1995: 53-58; 2001: 18-19), como o autor mais importante para a constituição do campo de estudos afro-brasileiros nas Ciências Humanas, foi Roger Bastide, o qual deu pouco destaque ao conceito de sincretismo. De acordo com Bastide (1971), a ideia de sincretismo lembrava fusão, mistura ou identificação, mas não implicava misturas ou identificações e, sim, semelhanças e equivalências.

Como sintetiza Ferretti (1999: 113), "sincretismo é uma palavra considerada maldita", pois muitos pesquisadores evitam mencioná-la, por considerarem seu sentido negativo, ou seja, como sinônimo de mistura confusa de elementos diversos, ou como uma imposição do evolucionismo e do colonialismo. O antropólogo holandês André Droogers - citado em Ferreti (1999: 113) - esclarece que o termo possui duplo sentido: um significado objetivo, neutro e descritivo de mistura de religiões e outro subjetivo por incluir a avaliação dessa mistura.

Discorrendo especificamente sobre o sincretismo, Moura (1988: 34) critica o fato de que o antropólogo e o sociólogo não tenham discutido suficientemente determinados conceitos que dizem respeito às relações entre quem tem herança cultural africana e/ou europeia no Brasil, como 
por exemplo, os conceitos de sincretismo, assimilação, acomodação e aculturação. Para o autor, ao se esquecer da posição e estrutura de etnias que possuem padrões de cultura diversos, a visão que se tem é de uma compreensão acadêmica do problema e não do processo da dinâmica social. Nas palavras do autor: "antes de examinarmos esses contatos culturais, temos de situar o modo de produção no qual eles se realizam, sem o que ficaremos sem possibilidade de analisar o conteúdo social desse processo" (Moura, 1988: 34).

Para Moura, é importante rever esses conceitos por se ligarem a uma ciência social colonizadora, sendo usada pelo colonizado. Para ele, a origem da Antropologia leva a perceber sua função inicial de "municiadora do sistema colonial", pois sua atividade prática buscou racionalizar o colonialismo, devido à sua posição eurocêntrica. É importante destacar a necessidade de reavaliar criticamente essa situação e "a herança ideológica que permeia e se manifesta em uma série de conceitos básicos, até hoje usados pelos antropólogos em nível significativo" (Moura, 1988: 35).

O que se pode depreender disso é que, permeando os discursos sobre o sincretismo, parece existir um discurso racista que permanece como um resquício da escravidão. Ou seja, escravidão e racismo se inter-relacionam a partir das ideologias raciais (cf. Ianni, 1988) juntamente com questões referentes ao preconceito que essa inter-relação pode gerar.

Peter Fry - citado em Ferretti (2001: 22) - afirma que os conceitos de pureza, mistura e sincretismo são construções essencialmente sociais e tendem a aparecer em ocasião de disputa de poder e hegemonia. Procurando interfaces produtivas para o estudo da linguagem em relação à sociedade, Fairclough (2001) afirma que o foco dos estudos atuais deve estar na mudança social e nas práticas discursivas que lutam por hegemonia, pois é dentro das práticas discursivas que os conceitos são construídos, mas é também dentro delas que ele pode ser desafiado, podendo, em alguns casos, levar a mudanças.

\section{O SINCRETISMO E A ANÁlise TEXTUAL PARA PESQUiSA SOCIAL}

Como fenômeno discursivo, o sincretismo parece articular discursos conflituosos que parecem permear a tensão na produção do texto e na construção do hibridismo que caracteriza o Brasil. 
Fairclough (1995) procura explicitar a relação dialética entre o discurso e a estrutura social, tomando por base que cada evento discursivo deverá sempre ser analisado como texto, prática discursiva e prática social, de forma que seja possível refletir a respeito da produção, da distribuição e do consumo dos textos. Segundo o autor, o discurso se materializa nos textos que são ao mesmo tempo exemplos de prática discursiva, por serem um local em que diferentes discursos estão em constante conflito, produzindo embates e estabilidades, e prática social, pois fazem parte de um momento específico de uma cultura se significando e ressignificando na sociedade da qual fazem parte. E é isso que comprova a própria natureza constitutiva da linguagem na sociedade. Do ponto de vista analítico, é importante frisar que essa visão tridimensional ocorre de forma imbricada, inter-relacionada, dificultando, inclusive, uma percepção seccionada do evento, o que pode ser feito apenas por razões didáticas.

Quanto à mídia, Fairclough (1995) a vê como representação, por isso ele chama a atenção para o fato de em qualquer representação se ter que decidir sobre o que incluir ou excluir e sobre o que estará em primeiro ou segundo plano, pois nesse momento representações, identidades e relações estão sendo construídas e engendradas discursiva e ideologicamente nas proposições do texto.

A Análise Crítica do Discurso (ACD), então, por ser uma teoria de base sistêmica (Fairclough, 1995, 2001), percebe o texto em sua relação com a sociedade e com a cultura, partindo desta noção para desenvolver a concepção de linguagem como prática textual, prática discursiva e prática social. Dentro dessa concepção, um texto deixa de ser apenas um texto e passa a ser visto como um evento discursivo capaz de, pelo uso da linguagem, gerar possíveis formas de legitimação do discurso a que estiver vinculado.

Este trabalho se afilia à $\mathrm{ACD}$ e integra o projeto de estudos da relação entre política e uso da linguagem, em especial em construções raciais brasileiras em gêneros diversos (Magalhães 2004), vinculado ao Projeto Corpus Discursivo para Análises Linguísticas e Literárias - Cordiall. Os resultados de uma pesquisa mais abrangente sobre o tema foram apresentados em Carmo (2005). Para o escopo deste artigo, parte-se da ocorrência da palavra-chave sincretismo em textos da mídia brasileira, considerados permeados pela interdiscursividade, ou hibridização de diferentes textos, gêneros e discursos. As categorias de acesso à interdiscursividade foram 
as colocações, as relações lexicais e a prosódia semântica, as quais foram analisadas com apoio das ferramentas da Linguística de Corpus.

O conceito de palavra-chave é usado aqui, de acordo com Williams (1976: 15), como "palavras significativas, que ligam certas atividades a sua interpretação; palavras significativas e indicativas de certas formas de pensamento".

Gênero, por sua vez, pode ser compreendido como um conjunto de convenções relativamente estável que é associado com, e parcialmente realiza, um tipo de atividade socialmente ratificada. A análise de gênero implica perceber um tipo particular de texto e também processos particulares de produção, distribuição e consumo dos textos (Fairclough, 2001: 161). Por isso o texto é concebido como o local em que os discursos se materializam e o discurso é o texto em relação a sua produção, distribuição e consumo. A realização do gênero nos textos que a eles se vinculam é analisada de acordo com os pressupostos teóricos da Linguística Sistêmico-Funcional LSF (Halliday, 1994).

A categoria de análise da LSF mais utilizada neste trabalho são as relações lexicais, principalmente, aquelas associadas às colocações de que faz parte a palavra sincretismo. O trabalho considerado seminal a respeito da colocação é o de Firth (1957) de onde Halliday \& Hasan (1976) tomaram emprestado o termo. Halliday \& Hasan não fazem muitas considerações a seu respeito e limitam-se à sua conceituação em termos de co-ocorrência de itens lexicais no mesmo ambiente e à exposição das dificuldades apresentadas em um estudo dessa categoria:

A análise e interpretação de um padrão lexical desse tipo é a maior tarefa dos futuros estudos sobre coesão textual. Aqui, apenas agruparemos todas as várias relações lexicais que NÃO dependem de identidade de referente e NÃO são, como a reiteração, acompanhadas pelo artigo definido ou por um demonstrativo - em outras palavras, toda coesão lexical que não está coberta pelo que temos chamado de 'reiteração' e as trataremos genericamente como COLOCAÇ̃̃̃ ou coesão colocacional sem tentar classificar as várias relações de significados com as quais está envolvida (Halliday \& Hasan, 1976: 287) ${ }^{1}$.

1. Minha tradução de: "The analysis and interpretation of lexical patterning of this king is major task in the further study of textual cohesion. Here we shall simply group together all the various lexical relations that do NOT depend on referential identity and are NOT of the form of reiteration accompanied by the or a demonstrative - in other words, all lexical cohesion that is not covered by what we have called "reiteration" - and treat it under the general heading of COLLOCATIONS, or collocational cohesion, without attempting to classify the various meaning relations that are involved" (Halliday \& Hasan 1976: 287). 
Segundo Halliday \& Hasan (1976: 288), o efeito da coesão lexical por colocação é sutil e difícil de estimar, pois todos os itens lexicais podem entrar em relação coesiva, mas tais relações não são explícitas nos próprios itens lexicais. No sentido dado por Halliday \& Hasan (1976), a colocação é uma propriedade estatisticamente identificável do léxico e seria por meio dessa propriedade que um item lexical poderia mostrar-se com a possibilidade de co-ocorrer mais provavelmente com certos itens que com outros.

Em Halliday \& Hasan (1976), os fatores que incidem sobre o fenômeno colocacional estão muito imbricados, mas, diferentemente, em Sinclair (1991), o fator proximidade no texto é preponderante e, em estudos como o de Stubbs (1996), principalmente no que tange à ideia de palavra-chave (agora como conceito criado por Michael Scott, para se referir à frequência pouco usual de um item lexical num dado corpus), o fator frequência de emprego se acentua. A semelhança dessas perspectivas pode ser atribuída à fonte onde os autores buscam fundamentação: os trabalhos de Firth. E as diferenças, é claro, decorrem da contribuição que cada um deles dá aos estudos sobre coesão, principalmente a partir de pontos de vista diferenciados inclusive pela possibilidade recente de armazenamento de textos e pela criação de programas de análise textual em computador.

As diferentes posições apontam também para uma diferença sobre a percepção do fenômeno colocacional na perspectiva da LSF e da Linguística de Corpus - LC. Para a primeira, o fenômeno depende de fatores nem sempre contidos no próprio léxico, uma vez que parte do princípio de que a colocação é uma propriedade textual ligada à proximidade no sistema lexical, à proximidade no texto e também à raridade de emprego. Isso significa que não há em si uma prioridade do léxico por si só na análise do fenômeno, ou seja, é preciso uma expansão ao texto para a investigação da colocação. Para a segunda, como se verá posteriormente, ela é um fenômeno lexical e estatístico, razão pela qual é computável. $\mathrm{Na}$ análise do fenômeno, dentro da LC, a base é lexical e, em primeira instância, não necessita da expansão para a categoria textual, nos moldes da LSF, embora admita certa expansão como no caso da prosódia semântica ou associação entre itens lexicais e a conotação (negativa, positiva ou neutra) de campos semânticos a qual pode ser analisada com base nas relações entre os itens e nas valorações nelas impressa.

No contexto da LC, conforme nos explica Berber Sardinha (2000a: 359; 2004: 40-41), o trabalho de descrição da linguagem se centraliza em 
três fenômenos, quais sejam: (1) a colocação ou associação entre itens lexicais, ou entre o léxico e campos semânticos; (2) a coligação ou associação entre itens lexicais e gramaticais; e (3) a prosódia semântica ou associação entre itens lexicais e a conotação (negativa, positiva ou neutra) de campos semânticos.

O nome prosódia semântica se deve ao fato de determinadas palavras prepararem o ouvinte ou o leitor para o conteúdo semântico que está por vir (cf. Berber Sardinha, 1999b) e a criação do termo é atribuída aos linguistas J. Sinclair e S. Partington (cf. Berber Sardinha, 2000b). Nesses termos, a prosódia semântica negativa se associaria a palavras desfavoráveis, a positiva, a palavras favoráveis e as neutras não indicariam valorações, ligando-se a palavras com conteúdo semântico que evocaria um campo semântico "imparcial”. Por isso, Hunston \& Francis (2000: 137) explicam que uma palavra pode ter uma prosódia semântica em particular se ela puder co-ocorrer com outras pertencentes a um determinado campo semântico, momento em que se pode relacionar prosódia semântica e formas padronizadas como a colocação.

Adotando essa perspectiva teórica e as categorias acima definidas, será feita uma crítica analítica da relação entre o sincretismo e a questão racial em dois corpora de jornais e revistas brasileiros.

\section{Corpus e Procedimentos metodológicos}

O corpus é composto de textos em que a palavra sincretismo aparece pelo menos uma vez, coletados de dois jornais ( $O$ Globo e Folha de $S$. Paulo) e duas revistas de informação geral (Veja e Época) no período de 1998 a 2003, com vistas a observar mudanças discursivas em um período de cinco anos de publicação.

É importante destacar que cada instituição afirma suas pretensões de suprir o leitor de informações de forma neutra e imparcial, o que, no senso comum, é aceito como prerrogativa do jornalismo. Pretende-se, após uma breve exposição sobre os veículos com base nas próprias informações dadas por eles mesmos, problematizar esse ponto de vista a partir de diferentes olhares sobre tais veículos.

De acordo com sua própria agência de notícias, $O$ Globo é um jornal diário ligado a uma agência reconhecida nacional e internacionalmente 
tanto pela qualidade quanto pela credibilidade de seu conteúdo - a Agência O Globo - a qual é responsável pelo fornecimento de reportagens, fotos, colunas, suplementos e cadernos especiais para mais de cem veículos de comunicação, no Brasil e no exterior. Segundo a própria agência, O Globo atinge 2 milhões de leitores aos domingos. Destes, $61 \%$ pertencem às classes A e B; $69 \%$ têm curso superior; $74 \%$ possuem renda familiar acima de 30 salários-mínimos. A faixa etária atingida gira dos 15 aos 65 anos. A tiragem dominical é de 660 mil exemplares.

A Folba de S. Paulo, por sua vez, foi fundada em 1921 e tornou-se, na década de 1980, o jornal brasileiro mais vendido no país (em 2003, por exemplo, a circulação média foi de 350 mil exemplares em dias úteis e 430 mil aos domingos). O crescimento do jornal deveu-se a estratégias baseadas nos princípios editoriais do "Projeto Folha: pluralismo, apartidarismo, jornalismo crítico e independência". Sua organização é feita em cadernos temáticos diários e suplementos de circulação nacional. Foi, também, o primeiro veículo de comunicação do Brasil a oferecer conteúdo on-line a seus leitores. A publicação em 1995 de uma edição especial sobre preconceito racial sob o título "Racismo cordial: a mais completa análise do preconceito racial" trouxe grande repercussão para o jornal. Em 1997, o jornal publicou a versão mais recente de seu projeto editorial, que propõe seleção criteriosa dos fatos a serem tratados jornalisticamente, abordagem aprofundada, crítica e pluralista, texto didático e interessante.

A revista Veja nasce de uma outra - a revista Veja e Leia, pertencente à editora Abril. A primeira edição de Veja foi datada de 11 de setembro de 1968, com tiragem de 695 mil exemplares, distribuídos por todos os estados brasileiros. Hoje, a tiragem de Veja gira em torno de 1.250.000 exemplares. Em termos de característica, Veja é uma revista semanal de informação, inspirada na revista americana Time, criada em 1922 por Henry Luce. É a primeira do gênero lançada no Brasil, onde imperavam no mercado editorial as revistas semanais ilustradas, com grandes fotos e textos curtos. Em termos estatísticos, a tiragem semanal (média) é de 1.250.000 exemplares, com um total estimado de leitores de cerca de 5 milhões (em média, 4 leitores por exemplar) e a carteira de assinantes é de 940.000, com leitores preponderantemente das classes A e B, de nível superior e de meia idade (Estudos Marplan, out./2002). Além disso, Veja é a quarta maior revista semanal de informação do mundo, sendo superada apenas pelas americanas Time, Newsweek e U.S. News and World Report. 
A revista semanal de informação Época, por seu turno, surgiu em 25 de maio de 1998 e ocupa um segundo lugar sólido no ranking da circulação das semanais, chegando a cerca de 500 mil exemplares por semana. A revista surgiu com um projeto gráfico inovador, inspirado na revista alemã "Focus", com a qual mantém um contrato de direitos autorais. A revista constrói sua imagem como informativa e isenta, procurando apresentar os fatos para permitir que o leitor julgue, interprete e decida. Pontos de vistas são enfocados em entrevistas, por colunistas e em artigos assinados.

Matos (1991), analisando O Globo e a Folha de S. Paulo, observou os assuntos das primeiras páginas desses jornais no período do governo de Emílio G. Médici e concluiu que a linha editorial dos jornais refletia a tensão do envolvimento que cada jornal tinha com o regime e o compromisso com a sociedade.

Barros $(1996,1997)$ analisou a Folba de S. Paulo buscando a relação que o jornal fez do processo de privatização no Brasil com o cenário internacional contemporâneo e verificou que, diferentemente do próprio projeto editorial do jornal, a partir do qual é proposta a realização de um jornalismo apartidário, pluralista, crítico e moderno, a privatização é ressaltada como uma necessidade histórica para o Brasil diante das tendências do mercado mundial e do cenário internacional. Segundo o autor, o jornal explorou a situação econômica brasileira nas duas décadas subsequentes, estabelecendo uma relação direta entre desestatização e superação da crise econômica, colocando a privatização como uma necessidade premente do país.

Carmo (1993) faz uma análise de três editoriais do jornal Folha de $S$. Paulo de maneira a tornar explícita a forma como o jornal avaliou o governo Itamar Franco em relação a questões sociais. Como o trabalho do autor mostra, a própria avaliação, seja positiva ou negativa, vai de encontro ao aspecto neutro ou imparcial dos jornais.

Mendes \& Magalhães (2003), pesquisa afiliada ao Cordiall, calcada no referencial da Análise Crítica do Discurso em interface com a Linguística de Corpus, analisa a representação dos discursos no noticiário policial dos jornais Folha de S. Paulo e O Dia. A pesquisa apontou que existem maneiras diferentes de construir a subjetividade dos leitores dos jornais e concluiu que isto se deve a questões ideológicas. Concluiu-se também que o estudo das ordens do discurso aponta tanto para relações de poder quanto para relações hegemônicas que norteiam a forma de representação dos fatos. 
Com relação à revista Veja, Pereira Jr. \& Müller (1998) demonstram, após um estudo sobre as conotações ideológicas da expressão "acadêmico", que os veículos de comunicação de massa ocupam um lugar central na construção da sociabilidade, frisando que as revistas semanais desempenham um papel extremamente importante na compreensão do mundo. Para os autores, as relações do homem com o mundo são cada vez mais construídas por esses veículos, pois são utilizados para fins informativos, para entretenimento e, inclusive, para a organização da vida cotidiana. Entretanto, os autores chamam a atenção para o fato de que esses veículos estariam contribuindo para a visão que as pessoas têm da sociedade. Magalhães \& Biavati (2003), por sua vez, analisam a construção de identidades de trabalho e de trabalhadores em propagandas da Veja, nas décadas de 1980 e 1990 e concluem que estas reproduzem ou constroem mudanças discursivas nas relações de trabalho ao longo de dez anos.

Com relação à revista Época, não foi encontrado um estudo específico, todavia o que as referências bibliográficas apontam é que não seria o caso, a priori, de se afirmar que esse ou aquele veículo possuía essa ou aquela intenção ao dar uma notícia, mas que uma análise detida seria capaz de apontar para ideologias subjacentes, ajudando a construir visões de mundo particulares. Nesse sentido, este trabalho pretende constituir mais uma contribuição para o estudo das relações sociais construídas a partir de práticas discursivas mediadas pela imprensa.

Por fim, cabe observar que apenas $O$ Globo e a revista Veja possuem informações sistemáticas sobre quem os lê, mas nenhum dos veículos aqui apresentados dão informações sobre grupos étnicos e raciais que comporiam a comunidade de seus leitores, o que sugere não ser tal informação de relevância no contexto brasileiro.

O programa utilizado para análise do corpus foi o WordSmith Tools, desenvolvido por Michael Scott (1996). Berber Sardinha (1999a, 2004) e Scott (2001) trazem uma explicitação dos componentes e das ferramentas encontradas no pacote do programa. Resumidamente, as ferramentas são: (1) WordList, responsável pela produção de listas de palavras; (2) Concord, responsável principalmente pela produção de listas de concordâncias, colocados, agrupamentos lexicais e de gráficos de distribuição da palavra de busca; e (3) KeyWords, responsável pela produção de uma lista de palavraschaves e de suas associações. 
A potencialidade do uso de corpora na pesquisa linguística tem sido salientada por diversos autores (ver, para mais considerações, Berber Sardinha, 1999a; 2004). As pesquisas desenvolvidas em Hardt-Mautner (1995), Stubbs (1996, 1997, 2001), Krishnamurthy (1998), o próprio Fairclough (2000a) no cenário internacional, e em Mendes \& Magalhães (2003) e Magalhães (2004), dentre outros, no cenário nacional, constituem importantes referências de trabalhos de análise textual que fazem uso de ferramentas da Linguística de Corpus como abordagem.

Os procedimentos metodológicos utilizados no levantamento de dados do corpus foram:

(1) coleta do corpus nos arquivos digitais dos jornais O Globo, Folha de S. Paulo, Veja e Época - via internet - dos textos em que apareceu pelo menos uma vez a palavra sincretismo, no período compreendido entre 1998 e 2003;

(2) confecção de tabela de frequência da palavra sincretismo, cujas palavras de mesma raiz não foram incluídas, para verificação estatística da palavra sincretismo, de modo a visualizar seu uso enquanto nódulo no corpus;

(3) confecção de tabela de frequência da palavra sincretismo, cujas palavras de mesma raiz foram incluídas (por meio da função lematizaşão no pacote WordSmith Tools), devido ao potencial coesivo das mesmas e à relação estabelecida como elemento de manutenção de um tema;

(4) confecção da lista de concordâncias com a palavra-chave sincretismo para análise do co-texto típico de sua ocorrência, juntamente com a prosódia semântica provinda dessas linhas;

(5) confecção da listagem dos agrupamentos lexicais, para o exame de possíveis padrões dos quais a palavra sincretismo fazia parte no corpus;

(6) confecção de tabelas de colocados e padrões de colocados para que fosse possível a observação dos padrões colocacionais da palavra sincretismo e a a análise das prosódias semânticas evocadas, com o intuito de traçar o perfil semântico para o lexema em questão;

(7) produção a partir das tabelas de colocados e padrões de colocados das principais relações lexicais e colocações, construídas com e/ou a partir da palavra sincretismo;

(8) confecção de uma tabela com as palavras mais frequentes no corpus, para verificação da relação delas nos textos

(9) busca das palavras mais frequentes;

(10) busca das principais relações lexicais formadas com a palavra sincretismo;

(11) verificação, a partir das linhas de concordância, dos temas a ela associados;

(12) análise do sincretismo como um aspecto discursivo da questão racial brasileira, partindo das relações lexicais e dos temas associados, seguindo os padrões da Análise Crítica do Discurso;

(13) contraste entre as análises feitas entre jornais e revistas de informação geral. 


\section{ANÁlise E disCuSSÃo das RELAÇÕES LEXICAIS DE SINCRETISMO}

Antes de partir para a análise propriamente dita da padronização da palavra sincretismo, é importante informar os dados gerais tanto do corpus quanto de cada subcorpus. Nesses termos, a Tabela 1, abaixo, mostra o número geral das palavras (types - tipos, tokens - ocorrências) e dos textos do corpus geral e de cada subcorpus:

Tabela 1: Dados gerais sobre o corpus e os respectivos subcorpora

\begin{tabular}{|l|l|}
\hline \multicolumn{2}{|c|}{ Corpus Geral } \\
\hline Tokens/ocorrências & 108.088 \\
\hline Types/tipos & 16.152 \\
\hline Número de textos Subcorpus d'O Globo \\
\hline \multicolumn{2}{|c|}{ Subcorpus da Folha de São Paulo } \\
\hline Tokens/ocorrências & 75.589 \\
\hline Types/ tipos & 20.942 \\
\hline Número de textos & 13.185 \\
\hline \multicolumn{2}{|c|}{ Subcorpus da Revista Veja } \\
\hline Tokens/ocorrências & 107 \\
\hline Types/ tipos & 3.728 \\
\hline Número de textos & 3016 \\
\hline \multicolumn{2}{|c|}{ Subcorpus da Revista Época } \\
\hline Tokens / Ocorrências & 8.137 \\
\hline Types / tipos & 2.853 \\
\hline Número de textos & 12 \\
\hline \multicolumn{2}{|c|}{} \\
\hline Tokens/ocorrências & 14 \\
\hline Types/ tipos & Número de textos \\
\hline
\end{tabular}

Conforme mostra a Tabela, o corpus todo possui 108.088 ocorrências de palavras, distribuídas em 16.152 tipos, num total de 163 textos. No caso d'O Globo, são 75.589 ocorrências, em 13.185 tipos, e 107 textos. O subcorpus da Folha de S. Paulo possui 20.942 ocorrências, 5.016 tipos, em 
seus 30 textos. Nas revistas, a Veja traz 3.728 ocorrências de palavras, distribuídas em 1.247 tipos, em seus 14 textos, enquanto a Época possui 8.137 ocorrências, 2.853 tipos e 12 textos.

No corpus como um todo, o nódulo da pesquisa ocorre 211 vezes, representando $0,19 \%$, porcentagem em relação ao número de palavras que constitui o corpus (cf. Tab. 2a). Com a lematização, esse índice sobe para 223 ocorrências, equivalentes a $0,20 \%$ (cf. Tab. 2b).

Tabela 2a: Dados sobre a frequência da palavra-chave sincretismo no corpus

\begin{tabular}{|l|l|l|l|l|}
\hline \multicolumn{5}{|c|}{ Ocorrências de sincretismo (palavra) no corpus } \\
\hline $\mathbf{N}$ & Word & Freq. & $\%$ & Lemmas \\
\hline 14547 & SINCRÉTICA & 3 & & \\
\hline 14548 & SINCRÉTICO & 4 & & \\
\hline 14549 & SINCRÉTICOS & 1 & & \\
\hline 14550 & SINCRETISMO & 211 & 0,20 & \\
\hline 14551 & SINCRETISMOS & 1 & & \\
\hline 14552 & SINCRETISTAS & 3 & & \\
\hline
\end{tabular}

Tabela 2b: Dados sobre a frequência da palavra-chave sincretismo no corpus, com lematização

\begin{tabular}{|l|l|l|l|l|}
\hline \multicolumn{5}{|c|}{ Ocorrência de sincretismo (lema) no corpus } \\
\hline $\mathbf{N}$ & Word & Freq. & $\%$ & Lemmas \\
\hline 14547 & SINCRÉTICA & 0 & & \\
\hline 14548 & SINCRÉTICO & 0 & & \\
\hline 14549 & SINCRÉTICOS & 0 & & \\
\hline 14550 & SINCRETISMO & 223 & 0,21 & $\begin{array}{l}\text { Sincréticos (1), sin- } \\
\text { crético (4), sincrética } \\
(3), \text { sincretismos (1), } \\
\text { sincretistas (3) }\end{array}$ \\
\hline 14551 & SINCRETISMOS & 0 & & \\
\hline 14552 & SINCRETISTAS & 0 & & \\
\hline
\end{tabular}


A opção por separar em duas tabelas a palavra sincretismo - uma com sua estatística em separado e outra utilizando a função lematização, ou agrupamento de duas ou mais formas da mesma palavra - decorre, em primeiro lugar, da necessidade de se terem dados estatísticos do nódulo da pesquisa, uma vez que a análise parte dele e é ele que encabeça as outras possibilidades derivacionais. Em segundo, não se podia deixar de considerar as palavras de mesma raiz, pois podem levar a significados semelhantes e exercem entre si força coesiva.

A repetição da palavra sincretismo e a ocorrência de palavras de mesma raiz parecem ser extremamente importantes na construção textual do corpus, pois constituem um mecanismo de coesão e indicam a possibilidade de agir como mecanismos de manutenção de tema e como redirecionador de discursos que, embora originalmente conflituosos, passam a confluir, mesmo quando há tensão nos textos, como se pode ver no trecho abaixo:

(1) Tiraremos a ordem dos desfiles pela temática dos trabalhos. Há muitas alusões à Guerra do Golfo e à guerra urbana com sincretismo religioso. Um trabalho apresenta conflitos e Nossa Senhora pedindo paz - explica. (Folha de S. Paulo)

Como se pode notar, o sincretismo é visto como um discurso "pacifista", capaz de acabar com conflitos e gerar confluência como se evidencia no exemplo abaixo:

(2) Dona Canô fala da confluência dos hinos católicos com os pontos de candomblé do sincretismo religioso baiano. Tom Zé teoriza que a letra da cantiga de roda "O cravo e a rosa" descreve o defloramento de uma virgem. O pesquisador Antônio Risério afirma que a malícia do Recôncavo é perceptível na voz de João Gilberto, que é de Juazeiro, em "A falsa baiana". E o músico Roberto Mendes avisa: ouvir Caymmi fora da Bahia, nem pensar. (O Globo)

Por outro lado, o exemplo (3) abaixo é um questionamento da questão do sincretismo no livro Casa-grande E Senzala de Gilberto Freyre, indicando a constante possibilidade de questionamento e de desafio de pontos de vista.

(3) Não é que Freyre tenha passado a distância das cruezas do escravismo colonial. Ele fala da violência contra os índios. Do sadismo que presidiu às relações entre senhor e escravo. Da opressão sobre os negros trazidos da África. Mas a verdade é que os conflitos, as dores e os antagonismos da vida brasileira ficaram diluídos em seu painel. Nesse sentido, o que temos, na obra de Freyre, é uma idealização senhorial de nosso passado, que acabou repercutindo em nosso presente. (Época) 
Talvez por isso, em todo texto em que a palavra sincretismo ocorre, parece ser ela que (re)arranja as outras palavras e/ou expressões de forma que não sejam tidas como discrepantes ou conflituosas no lugar em que ocorrem. Dessa maneira, palavras indicadoras de discursos diferentes (do candomblé, da umbanda, do catolicismo, do islamismo etc. ou de campos diferentes como religião, música, teatro, shows etc.) são utilizadas no mesmo texto sem causar estranheza. Nesses termos, juntamente com palavras de mesma raiz, ela parece trazer coesão ao texto como um todo e ajudar na manutenção dos campos e apaziguamento/atenuação da tensão entre os diversos discursos chamados ao diálogo nos textos, como se pode ver no artigo abaixo, retirado da Folha de S. Paulo como exemplo².

\section{A fé do povo ou no povo?}

Dois filmes, atualmente em cartaz no país, são documentários brasileiros sobre religião: "Fé" e "Santo Forte". A religião talvez seja a coisa mais importante que existe na sociedade. Religião vem de "religare", aquilo que liga a comunidade, a tribo, o país.

O cimento espiritual da cultura é a religião, de modo que pode ser tanto o ópio do povo quanto a vitamina para o fraco. Depende de como funciona a fé em uma determinada sociedade.

No caso do Brasil, os melhores cientistas e artistas são pessoas que se dedicam a refletir sobre a particularidade do nosso sentimento religioso.

Somos o país da figa e da cruz, do Omolu e do Padre Eterno, de Ogum e de São Jorge, de Exu e São Judas Tadeu.

Misturamos santos católicos e orixás africanos com reminiscências indígenas. Cruzamos divindades de origem diversa. É comum ver preto macumbeiro exigindo exéquias católicas na hora da morte, assim como é frequente assistirmos a pai de família igrejeiro pedindo ao candomblé um bom casamento para a filha.

O fato é que corre muita superstição nas veias do povo brasileiro. Herdamos esse patrimônio de Portugal.

O número 13 dá azar. Não convém passar por debaixo da escada. Titica de galinha cura espinha. Acredita-se que simpatia dá jeito no câncer. Cão uivando é mau agouro.

Os estudiosos designam a mistura de crendices e religiões pelo termo SINCRETISMO. Ou seja: amalgamamos crenças heterogêneas. Somos crédulos. Padre Antônio Vieira dizia

2. Nele, optou-se por negritar palavras que possam indicar vieses ou discursos diferentes, para que seja possível visualizar a diversidade discursiva e a confluência que a ideia de sincretismo traz. 
que o medo é crédulo. Nosso medo primário é morrermos sem sepultura. Sem sepultura surge o espectro do morto vivo. Alma penada. Zumbi.

Nossa tendência é acreditar em tudo: tanto na eficácia do despacho ou do ebó quanto no mistério da Santíssima Trindade. É difícil estabelecer com precisão em que o povo brasileiro não acredita. Temos uma feijoada dentro da nossa alma mística.

Há quem diga que o sentimento religioso no Brasil é unificado pelo símbolo da cruz. Cristo na cruz e fora da cruz. Em Minas Gerais é comum ouvir a oblação a São Cristinho, o diminutivo do convívio íntimo.

Engano supor que a indústria ou a culinária do McDonald's faça desaparecer o sentimento tumultuário da religiosidade entre nós.

Muda-se a forma, mas não o conteúdo.

Basta observar o que está acontecendo com a incorporação da parafernália acústica pop pela renovação carismática, na qual o ouvido do fiel é o ouvido discoteca, aglutinando-se em torno de um "Xoumissa", espécie de performance catártica que mistura samba, futebol e Carnaval.

Ao que tudo indica, é pela gestuália do barulho que se ouve a voz da divindade.

Até mesmo ateus convictos se garantem diante da ameaça assombrosa: quem não acredita em Deus no Brasil morre louco.

Gilberto Vasconcellos é professor de Ciências Sociais da Universidade Federal de Juiz de Fora (MG) e autor de "O Príncipe da Moeda" (ed. Espaço e Tempo), entre outros.

Como se pode ver no texto, existe uma profusão de itens lexicais de campos diferentes, como religião, ciência, artes, música e esporte (religião, cientistas, artistas, culinária do McDonald's, samba, futebol, carnaval). Os itens relacionados ao campo religioso mostram o discurso do cristianismo, o da religiosidade de herança africana e também o das crendices populares (religião, fé, Santo Forte, figa, cruz, Omolu, Padre Eterno, Ogum, São Jorge, Exu, São Judas Tadeu, São Cristinho, Renovação carismática, fiel, voz da divindade, Deus, Despacho, ebó, mistério da Santíssima Trindade, alma penada, número 13, azar, simpatia, mau agouro, alma mística).

Ao mesmo tempo, itens como comunidade, tribo, país, podem indicar as etnias formadoras do Brasil, como as comunidades africana e europeia, e as tribos indígenas. Por isso, Gilberto Vasconcellos frisa a palavra SINCRETISMO em letras maiúsculas e afirma que "misturamos santos católicos e orixás africanos com reminiscências indígenas. Cruzamos divindades de origem diversa". E faz a relação entre o preto macumbeiro que exige exéquias católicas no momento da morte e o pai de família igrejeiro que pede ao candomblé um 
bom casamento para a filha. Essa também pode ser a razão pela qual o autor utiliza a expressão sentimento tumultuário da religiosidade. Nesses termos, pode-se perceber que o uso da palavra sincretismo pode desfazer possíveis estranhamentos quanto à utilização de itens e temas diferentes num mesmo texto, caracterizadores de uma feijoada, conforme item utilizado por Gilberto Vasconcellos.

\section{ANÁlise E DisCuSSÃo dAS RELAÇÕES LEXICAIS ENTRE SINCRETISMO E A QUESTÃO RACIAL}

Foi interessante observar, ainda, a ocorrência de itens lexicais associados à questão racial. No corpus, as palavras branco, brancos, branca e brancas totalizam 97 ocorrências e, com um leque de derivações/flexões bem maior, negro totaliza 216 ocorrências (negões, negra, negras, negreiro, negreiros, negrinho, negritude, negro, negros, neguinho). Nessa relação, fica claro o quanto o fenômeno sincretismo diz mais respeito aos descendentes de africanos, uma vez que a frequência também pode indicar como a palavra negro é mais marcada nos textos.

Os discursos sobre o sincretismo remetem, nesse sentido, ao discurso de dominados e dominantes numa relação de embate, remontando principal e historicamente aos assuntos escravidão (97 ocorrências da palavra escravo e suas flexões ou derivações escrava, escravas, escravatura, escravidão, escravismo, escravista, escravizadas, escravocrata, escravocratas, escravos) e colonialismo (57 ocorrências da palavra colônia e de suas flexões ou derivações: coloniais, colonial, colonialismo, colonialista, colonialistas, colônias, colonização, colonizador, colonizadores, colonos). Por isso chama a atenção o fato de a associação a esses assuntos criar uma prosódia semântica negativa (conotação), como em "O sincretismo é um resquício da escravidão" (O Globo) ou nos trechos abaixo:

(4) Na apresentação Carlos Diegues, cineasta filho do etnólogo alagoano Manuel Diegues Júnior, se refere ao ponto de partida de investigação do autor: o negro perdura como negro no tempo brasileiro, não obstante a miscigenação no sangue e o sincretismo na alma. (Revista Época)

(5) A isso, acrescente-se, conforme sabemos da sociologia do açúcar, que na cultura popular os rios de Portugais encontram-se nas águas do Capibaribe. Ou seja: o negro no Brasil é invenção do açúcar explorado pelo colonizador português latifundiário. (Folha de S. Paulo) 
No exemplo (4), há uma separação interessante entre o aspecto físico representado pela miscigenação e uma ideia de sincretismo que o transcende, evocando talvez os diversos problemas pelos quais os descendentes de africanos passam como resultado da exclusão de diversos tipos, possivelmente oriundos na constituição do país. Nele, pode-se inferir também uma ideia de negação da "pureza" que não se verifica no Brasil, principalmente hoje - no tempo brasileiro, nem se verificou a partir do contato entre os povos que o constituíram. Por isso, houve o uso do verbo perdurar, que pode indicar a permanência de uma ideia e o atraso com relação a uma mudança de pensamento da própria sociedade brasileira que, de uma forma ou de outra, ainda ajuda na manutenção da subalternidade do descendente de africano. A expressão miscigenação no sangue evoca mais uma vez o discurso de raça biológica, ao passo que a expressão sincretismo na alma evoca a possibilidade de transcendência e uma possível ligação da religião com o processo de branqueamento. Ou seja, parece haver uma constatação das ideologias que sustentam os processos de diferenciação e exclusão social dos descendentes de africanos.

O exemplo (5) traz à tona a história da colonização do Brasil e também uma percepção social e econômica como justificativa para a situação dos descendentes de africanos hoje. A dimensão ideológica sugerida na frase é de uma situação inferior, que se sustenta apenas no processo de exploração que se iniciou no passado. Ou seja, de formas diferentes, os dois exemplos procuram retratar a situação menos favorecida dos descendentes de africanos como um resultado da colonização que se originou em interesses econômicos, de poder e dominação e que teve como um dos resultados a escravidão que marcou os africanos no passado, e ainda ecoa na vida de seus descendentes atualmente.

Talvez, por isso, tenha havido 53 referências a questões raciais distribuídas entre a ocorrência exata da palavra raça e dos seguintes derivados ou flexões: raças, raciais, racial, racialmente, racismo, racistas. Com relação à etnia e seus derivados/flexões tem-se um número maior de variedades, mas um número próximo de ocorrências (46): etnias, étnica, étnicas, étnico, étnicos, etnocêntricos, etnografia, etnográfica, etnográfico, etnógrafo, etnológicos, etnólogo, etnólogos, etnomusicologia. Essa diferença pequena pode apontar a luta entre um discurso racista em que se sustentam os processos de diferenciação entre superiores/inferiores, dominantes/dominados na forma de exclusão 
em moldes biológicos e um discurso acadêmico contrário que afirma a diferenciação em termos identitários, com a possibilidade de escolha e negação do caráter físico na identificação. Em outras palavras, se uma das formas de identificação de raça são traços físicos como a cor da pele, o tipo de cabelo, dentre outros, uma outra maneira de se identificar seria do ponto de vista étnico em que o pertencimento a uma cultura seria o ponto fulcral da identificação.

Por isso, o discurso antissincretista tem ganhado força, principalmente no campo religioso, imprimindo no termo conotações negativas ("Crítica do sincretismo, Mãe Stella prega a fidelidade ao rito"; "Ela é contra o sincretismo religioso"; "O sincretismo enfraquece os dois lados"; "sincretismo que remonta à época da colônia"; "Da nossa parte, o anti-sincretismo é também uma questão política"; "O sincretismo não tem mais lugar" - revista Época).

Esse dado ajudaria a explicar, também, as razões pelas quais há campos iguais tanto ajudando a criar uma prosódia semântica positiva quanto negativa para a palavra sincretismo e mesmo o porquê de a religião ser o campo mais expressivo no corpus. Foram totalizadas 349 ocorrências da palavra religião e de seus derivados e flexões (religiões, religiosa, religiosas, religiosidade, religiosidades, religioso, religiosos). Houve ainda duas ocorrências da palavra latina religare e duas da inglesa religious.

A distribuição das prosódias no corpus pode ser disposta no Gráfico 1, abaixo:

Negativa; Neutra; 9

60

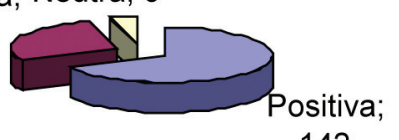

142

Gráfico 1: Prosódia semântica da palavra sincretismo 
Em termos conceituais, mistura é o significado mais atribuído ao termo, pois são 91 ocorrências de palavras que ligam sincretismo a mistura: misto, mistura, misturá-, misturada, misturadinho, misturado, misturados, misturam, misturamos, misturando, misturar, misturaram, misturas, misturavam, misturou.

Nos exemplos abaixo, foram retirados os conceitos e formas de caracterização do sincretismo nos textos estudados e organizados de acordo com os veículos em que foram encontrados:

(6) O Globo

(a) O sincretismo religioso foi a saída encontrada pela agremiação para driblar a santa polêmica.

(b) O sincretismo, cheio de ideias originais, misturando sambalanço, pilantragem e black com muita acid-MPB.

(c) Uma fé não anula a outra. O que talvez explique o que chamamos de sincretismo. Misturar crenças, dogmas, seitas, altares, santos e até deuses seria assim uma forma de proteção total, de cercar pelos sete lados os fluídos que vêm não sabe de onde.

(d) O brasileiro tem devoção a tudo. A essência do enredo é falar dessa religiosidade e do sincretismo provocado pela mistura de raças - explica Sérgio Murilo.

(e) RELIGIÃO: Mart'nália assume seu sincretismo: "Religião brasileira, uma mistura de catolicismo e macumba."

(f) O sincretismo se dá na África como no Brasil. Misturamos elementos da magia com os do islamismo. No Brasil, vocês misturam os elementos africanos com os do catolicismo. (Kourouma - escritor africano).

(g) Negar o sincretismo é prova da independência de uma religião. Você pode até ir à missa e ao candomblé, mas não mistura santo com orixá. O sincretismo é resquício da escravidão, o senhor queria que o negro fosse católico e ele, para agradar, dizia que era. Mas agora somos livres mesmo, não precisamos disso. (Mãe Stella)

(h) Identificado com a ala conservadora da Igreja, desde o primeiro momento no cargo, ele [Dom Lucas Moreira Neves] combateu o sincretismo religioso, uma marca da cultura baiana, que associa o catolicismo ao candomblé, chegando a proibir a lavagem das escadarias da Igreja do Senhor do Bonfim.

(i) ... Mãe Stella responde hoje com a aproximação entre as religiões. Mas desde os anos 70 lidera com energia um polêmico movimento contra o sincretismo, que no Brasil tradicionalmente superpôs santos e orixás, Igreja e terreiro.

(j) "sincretismo religioso é uma das características mais enriquecedoras das culturas" (Anna Bella).

(k) Negar nosso sincretismo religioso é uma loucura tão preconceituosa como negar o vigor da nossa cultura mulata. É essa mestiçagem que faz a originalidade da cultura brasileira e oferece a nossa contribuição de tolerância para o resto do mundo.

(l) Dona Canô fala da confluência dos hinos católicos com os pontos de candomblé do sincretismo religioso baiano. 
(m) Mas queremos que o povo saiba que no Brasil, um país com grande sincretismo religioso, a única coisa que se promove é a paz.

(n) Ela [Mãe Stella] sente-se no dever de afirmar que o sincretismo é danoso quando compromete a verdade do rito cristão e a expressão da Fé, em detrimento de uma autêntica evangelização".

(o) Num dos trechos mais aplaudidos de seu discurso, dom Geraldo defendeu o sincretismo religioso baiano como forma de expressão da fé e condenou a escravidão dos negros africanos...

(p) O sincretismo religioso é uma das características mais enriquecedoras das culturas analisa ela [Anna Bella, artista plástica], que tem origem judaica.

(7) Folha de S. Paulo

(a) Informado, como tinha de estar, pelas teorias da época, Arthur Ramos apostou pesado na ideia do sincretismo - da mistura "comportada" de credos e em uma espécie de processo evolutivo que faria com que as formas religiosas mais acabadas absorvessem as demais...

(b) Os estudiosos designam a mistura de crendices e religiões pelo termo sincretismo. Ou seja: amalgamamos crenças heterogêneas.

(c) Além disso, como os orixás foram "assimilados" aos santos católicos, "ao abrigo de um aparente sincretismo, as antigas tradições mantiveram-se através do tempo". "Todo mundo ficava contente: o governo, ao dividir para melhor reinar e garantir a paz do Estado; os escravos, por cantar e dançar; as divindades africanas, por receber as louvações; e os senhores por ver sentimentos tão católicos em seus cativos". (Pierre Verger - Antropólogo e Babalaô)

(d) Após um balanço teórico cuidadoso, a autora [Maria Isaura Pereira de Queiroz] define o "sincretismo" religioso como um processo não de fusão, mas de justaposição de partes (o que já havia sido notado por Nina Rodrigues), que permitiria ao negro resistir e preservar algo da "África no Brasil".

(e) A obra do sincretismo não conhece mais limitações. A macumba invadiu todas as esferas." Nessa osmose psicocultural o jovem cientista chamava a atenção para o fato de que isso tinha funções importantíssimas na produção da realidade nacional, ou seja, não era só reflexo mágico-emocional na superestrutura ideológica. (Roberto Felisberto Vasconcelos, acerca de Arthur Ramos)

(f) Não é fácil aos 6 anos escrever um tratado original, de acordo com o padrão da mais rigorosa pesquisa universitária, acerca do sincretismo religioso na sociedade brasileira, isto é, a simbiose de santos católicos, de orixás africanos e de mitologia ameraba. (Roberto Felisberto Vasconcelos, acerca de Arthur Ramos)

(8) Veja

(a) O grupo [Camaleão], que foi uma das grandes revelações do Free Jazz Festival 2001, mostra esta noite o sincretismo cultural no palco do Lapa. O som é resultado de uma mistura de ritmos indígenas, batida percussiva dos negros, além de reisado, ritmo desenvolvido pelos agricultores do povoado de Caraíbas, e o candomblé. 
(b) No enredo está o sincretismo de religiões, um dos traços mais marcantes da cultura baiana.

(9) Época

(a) Ela [Mãe Stella é contra o sincretismo religioso - associação entre santos católicos e santos do candomblé.

(b) Dom Gílio é militante de longa data das pastorais de negros. Cumpriu dois mandatos como presidente do Instituto Mariama, instituição que reúne padres, bispos e diáconos negros e se dedica a estudar a espiritualidade afro-brasileira. Para ele, o sincretismo é um assunto que deve ser estudado e tolerado pela Igreja Católica. "Existe profunda identidade entre a fé católica e o candomblé", afirma o bispo.

(c) $\mathrm{Na}$ Bahia, o sincretismo religioso sempre foi um assunto delicado para as autoridades eclesiásticas. É uma herança antiga, ainda do tempo da escravidão. (Cíntia Campos)

(d) "Sincretismo é resquício da escravatura." (Mãe Stella)

(e) Os mitos da criação do mundo da Nação Nagô são muito semelhantes aos do livro do Gênese, na Bíblia. Por isso, o sincretismo é uma realidade que desafia a ação pastoral.

Esses trechos ajudam a corroborar a ideia de mistura como sendo o significado mais atribuído ao termo sincretismo, uma vez que ocorrem em 10 definições e trechos que procuram caracterizar esse fenômeno social, cultural e religioso (6a, b, c, d, e, f, g; 7a, b; 8a, b). Também é relevante frisar o campo da religião como mais produtivo e associado ao sincretismo dentro dos conceitos e processos de caracterização do fenômeno. Apenas dois trechos não dizem respeito a questões religiosas, abordando o campo da música (6b; 8a), mesmo assim, no exemplo $8 \mathrm{a}$, ainda há a referência ao Candomblé.

Em termos conotativos, há uma equiparação entre uma percepção positiva e outra negativa do fenômeno, uma vez que há 15 conotações positivas $^{3}$ e 14 negativas ${ }^{4}$. O maior contraste ocorre com relação às revistas, pois a Veja traz o sincretismo como positivo e a Época como negativo em todos os trechos, pois de fato traz a ideia da diferença dentro dos textos, ao trazer o discurso antissincretista que busca, sobretudo, extirpar os elementos não considerados africanos em sua essência dos templos religiosos

3. A conotação é positiva nos trechos $6 \mathrm{~b}, \mathrm{c}, \mathrm{d}, \mathrm{e}, \mathrm{f}, \mathrm{j}, \mathrm{k}, \mathrm{l}, \mathrm{m}, \mathrm{o}, \mathrm{p} ; \mathrm{7d} ; 8 \mathrm{a}, \mathrm{b}$.

4. A conotação é negativa nos trechos $6 \mathrm{a}, \mathrm{g}, \mathrm{h}, \mathrm{i}, \mathrm{n} ; \mathrm{7a}, \mathrm{b}, \mathrm{c}, \mathrm{e}, \mathrm{f} ; 9 \mathrm{a}, \mathrm{b}, \mathrm{c}, \mathrm{d}, \mathrm{e}$. 
do Candomblé. Dessa forma, deve-se destacar o aspecto valorativo tanto dos conceitos quanto das características, uma vez que nem um dos trechos possui conotação neutra.

As ideias de miscigenação (6a), confluência (6 l) e justaposição (7d) constroem uma conotação positiva para o fenômeno quando se procura conceituar o termo. No primeiro caso, pela ideia de mistura e nos outros dois casos pela possibilidade de junção e equiparação, inerentes aos vocábulos.

As palavras associação (6h; 9a), superposição (6i), assimilação (7c), osmose psicocultural (7e) e simbiose (7f), por sua vez, constroem uma conotação negativa. Nesse específico caso, a negatividade ocorre porque a semântica das palavras - à exceção do item associação - apontam um processo associativo em que fica previsto algum tipo de prejuízo a uma das partes e, nesse sentido, historicamente, os descendentes de africanos têm constituído o grupo prejudicado.

Em termos linguísticos, é possível delinear - quando não ocorre um caso de explicitação longa do termo para ligá-lo à ideia de mistura - um padrão utilizado na produção do conceito de sincretismo a ser veiculado e também das formas para sua caracterização. A forma mais recorrente é a de uso de um processo relacional - em negrito nos trechos - seguido de um identificador (6k; 7d; 9b, c, e) ou atributo ${ }^{5}$ (6a, g, j, n, p; 9d) - grifados nos trechos. Ainda é possível perceber as formas apositivas (6h; 8b; 9a) e estruturas de ratificação com o uso das locuções ou seja ou isto é (7b, f).

\section{CONSIDERAÇÕES FINAIS}

O nódulo desta pesquisa - a palavra sincretismo - mostrou-se relevante para se levantar os discursos que se articulam dialogicamente na representação desse fenômeno social, para se procurar compreender alguns aspectos da questão racial brasileira. Nesses termos, deve-se ressaltar que, permeando esses discursos, a análise sugere a existência de um discurso racista que funciona como um sustentáculo das diferenças que se refletem tanto no meio social quanto econômico, religioso e identitário. A insatisfação com

5. Essa classificação segue os padrões de Halliday (1994) e Thompson (1996). Embora haja algumas controvérsias quanto à classificação de alguns termos em atributivos ou identificadores, não constitui aqui um objetivo entrar no mérito da questão. 
sua própria história e possibilidade de refletir sobre ela parece estar gerando modificações ou transformações no posicionamento dos descendentes de africanos com relação a sua própria condição social, cultural, econômica e religiosa. À medida que se rearticulam os discursos representados nos textos do corpus principalmente pelas palavras "brancos" e "negros", num processo associativo de dominantes e dominados, em relação à situação do descendente de africano, o antissincretismo toma voz em reação ao sincretismo, por este último ser fruto das ideologias que sustentam as desigualdades sociais que subalternizam os descendentes de africanos, devido à permanência das ideologias do branqueamento, da mistura cultural, social e religiosa perfeita e da democracia racial.

Pensar em um discurso que nega o sincretismo só faz sentido quando se percebe, por exclusão, que existe um discurso que lhe é favorável. E é importante averiguar as razões pelas quais existe um discurso midiático de sustentação de uma noção de sincretismo utilizada para a manutenção de um discurso hegemônico que representa a questão racial brasileira como democrática e as relações que ele pode ter com a manutenção do discurso dominante. Ou seja, o sincretismo parece ser um discurso hegemônico associado a uma democracia inexistente e o discurso antissincretista parece surgir em reação a ele, em resposta a esse discurso hegemônico, lutando por inserção na sociedade e causando tensão discursiva.

O antissincretismo parece estar demonstrando a possibilidade de revalorização do descendente de africano e de sua herança cultural. Conforme aponta Figueiredo (2002: 104), já nascemos embranquecidos por causa da predominância dos aspectos da "cultura branca", mas só enegrece ou se torna "negro" ao longo dos anos quem opta por incluir em sua vida aspectos que o identifiquem com a "cultura negra", tornando-se curioso em conhecer seu passado e também sua história.

Nesse sentido, as relações lexicais formadas por colocação com a palavra-chave sincretismo, seus colocados e associações a campos diversificados podem ser vistos como aspectos da incorporação de discursos e de como eles se imbricam para criação e (re)formulação do pensamento brasileiro, pois, paralelamente ao embranquecimento iniciado no passado, parece estar ocorrendo, por outro lado, uma retomada dos elementos da herança cultural africana, como fruto de uma revalorização do descendente de africanos e de sua cultura, o que explicaria o uso da expressão antissincretismo e os 
pontos de vista contrários ao fenômeno. Com relação ao uso do conceito de sincretismo como mistura nos textos, é então importante observar que, por essa razão, apenas uma única ocorrência da palavra sincretismo parece tornar capaz de camuflar e aparentemente resolver os conflitos expressos na tensão entre os discursos construtores do hibridismo brasileiro, em termos religiosos, culturais, econômicos, identitários e sociais, o que está sendo desafiado pelo discurso antissincretista, o qual traz junto consigo o discurso da (re)africanização. Silva (1999) denomina ainda outros como o da descatolização, desbantualização e iorubanização, mas todos eles ligados aos anteriores. As palavras de mesma raiz, por sua vez, do ponto de vista linguístico em termos da constituição dos textos, parecem ajudar na manutenção desse processo de mascaramento, criando coesão na tessitura do texto e ajudando a manter a atenuação e/ou o apaziguamento dos conflitos entre os campos e discursos que se apresentam na arena midiática.

Analisando-se as colocações e associações lexicais da palavra sincretismo, percebe-se que a produção dos textos e discursos que veiculam a noção de sincretismo mostra-se oscilando entre estar a favor ou negá-lo, mas não apenas na mídia. Por isso, como o sincretismo é uma realidade ligada à própria constituição híbrida do Brasil, essa palavra parece ser uma das palavras-chave para o entendimento da diversidade brasileira, em termos discursivos. Como item lexical, parece ser não apenas organizador das relações lexicais e nódulo causador das confluências dos campos associados, mas o elemento que permite a coesão textual, por redirecionar diferentes discursos e campos, muitas vezes conflituosos, e ligá-los de forma "pacífica" em torno de si enquanto cabeça das possibilidades relacionais e direcionador de campos e discursos. O item lexical sincretismo pode ser considerado um dos elementos-chave para uma percepção da questão racial brasileira, ainda com fortes laços nas ideologias que geram desigualdades sociais e processos de exclusão, uma vez que a linguagem é um construto social dialógico, permeado por ideologias e valores sociais sujeitos a mudanças, mas também capazes de levar a mudanças ou reproduzi-las no tecido social, indicando os movimentos pelos quais determinado pensamento passa.

A análise discursiva calcada nas relações lexicais mostrou-se produtiva e capaz de levantar questionamentos relevantes dos pontos de vista social e cultural, quando são percebidas tensões discursivas opacizadas por fenômenos contraditórios. A análise sugere que ainda há necessidade de um espaço para os discursos dos e sobre os descendentes de africanos na mídia, que 
permita visibilidade na diferença, que se projete em diferentes esferas da sociedade, de forma mais positiva e menos estereotipada.

Nossas reflexões acerca do sincretismo pretendem sugerir isso e, ao mesmo tempo, indicar um caminho importante de interfaces entre diferentes campos do saber que encontram no outro um apoio capaz de gerar contribuições válidas para ambos. O sincretismo é um fenômeno tradicionalmente estudado pela Antropologia, entretanto, nosso trabalho revela que olhares diferentes geram contribuições diferentes, em prol do questionamento de situações que ainda causam "mal-estar" social, por se associarem a e ecoar discursos voltados ao preconceito e geradores de assimetria. Foi possível refletir, por exemplo, sobre o quanto ideologias ligadas ao período escravocrata ainda permeiam nossa sociedade e sobre o quanto ainda carecem de atenção de pesquisadores que podem, num esforço interdisciplinar, apontar caminhos para uma sociedade mais humana, capaz de conviver com e respeitar as diferenças.

Recebido em setembro de 2007

Aprovado em maio de 2009 E-mail: claudiocarmo@mgconecta.com.br

\section{REFERÊNCIAS BIBLIOGRÁFICAS}

Barros, A. T. 1996. Cenário internacional e o discurso da Folha de São Paulo sobre a privatização no Brasil. Tuiuti: ciência e cultura, Curitiba: s.n, v. 5, n. 1, p. 24-32, mar.

. 1997. Estado versus mercado no discurso da Folha de São Paulo sobre a privatização no Brasil. Ciências e Letras, Porto Alegre: s.n, n. 20, p. 55-70, nov.

BAstide, R. 1971. As religiões africanas no Brasil: contribuição a uma Sociologia das interpenetrações de civilizações. São Paulo: Pioneira, 1971.

Berber Sardinha, T. 1999a. Usando WordSmith Tools na investigação da linguagem. DIRECT Paper 40. Disponível em: http://www2.lael.pucsp. br/direct/DirectPapers40.pdf. Acesso em: 11 abr. 2010.

. 1999b. Estudo baseado em corpus da padronização lexical no português brasileiro colocações e perfis semânticos. In: PROPOR'99. IV Encontro para o Processamento Computacional da Lingua Portuguesa Escrita e Falada, Évora, p. 269-287. 
2000a. Linguística de Corpus: histórico e problemática. D.E.L.T.A., São Paulo, vol 16, n. 2, p. 323-367.

. 2000b. Prosódia semântica na tradução do português e inglês: Um

estudo baseado em corpus. In: PROPOR 2000, V PROPOR - Encontro para o Processamento Computacional da Lingua Portuguesa Falada e Escrita, Atibaia, p. 93-104. . 2004. Linguística de Corpus. Barueri-SP: Manole.

Bloor, M.; Bloor, T. 2007. The Practice of Critical Discourse Analysis: An Introduction. London: Hodder Arnold.

CARmo, C. M. 2005. Relaçôes lexicais, interdiscursividade e representação: o sincretismo e a questão racial em corpus de jornais e revistas brasileiras. Tese de Doutorado. Belo Horizonte: UFMG.

Carmo, S. I. S. 1993. Luz e sombra nos editoriais da Folha de São Paulo. Perspectivas, São Paulo: s.n, v. 16, p. 255-263.

CunHa, A. G. 1982. Dicionário etimológico Nova Fronteira da língua portuguesa. Rio de Janeiro: Nova Fronteira.

Fairclough, N. 1995. Media Discourse. London: Longman. . 1999. Linguistic and intertextual analysis within discourse analysis.

In: Jaworsky, A.; Coupland, N. (Eds.). The Discourse Reader. London/ New York: Routledge, p. 183-220.

. 2000. New Labor, New Language? London: Routledge. . 2001. Discurso e mudança social. Brasília: UnB.

FerRetti, S. F. 1995. Repensando o sincretismo. São Luís: FAPEMA. . 1999. Sincretismo afro-brasileiro e resistência cultural. In: CAROSO, C. \& BACELAR, J. (Orgs.). Faces da tradição afro-brasileira: religiosidade, sincretismo, antissincretismo, reafricanização, práticas terapêuticas, etnobotânica e comida. Rio Janeiro: Pallas, p. 113-130.

. 2001. Notas sobre o sincretismo religioso no Brasil - Modelos, limitações, possibilidades. Tempo, Rio de Janeiro, n. 11, p. 13-26.

Figueiredo, A. 2002. Novas elites de cor: estudo sobre os profissionais liberais negros de Salvador. São Paulo: Annablume.

Firth, J. R. 1957. Papers on Linguistics, 1934-1945. Oxford: Oxford University Press.

Freyre, G. 1961. Casa-grande e senzala. Rio de Janeiro: Jose Olympio. Halliday, M. A. K. 1994. An Introduction to Functional Grammar. London: Edward Arnold. 
Halliday, M. A. K.; Hasan, R. 1976. Cohesion in English. London: Longman.

Hardt-Mautner, G. 1995. 'Only Connect.' Critical Discourse Analysis and Corpus Linguistics. Disponível em: www.ceng.metu.edu.tr/ e121058/ vol6.pdf. Acesso em: 11 abr. 2010.

Hunston, S.; Francis, G. 2000. Pattern Grammar: A Corpus-Driven Approach to the Lexical Grammar of English. Amsterdam: John Benjamins Publishing Company.

IANNI, O. 1988. Escravidão e racismo. São Paulo: Hucitec.

Krishnamurthy, R. 1998. Ethnic, racial and tribal: the language of racism? In: Caldas-Coulthard, C. R. \& Coulthard, M. (Eds.). Texts and Practices: Readings in Critical Discourse Analysis. London/New York: Routledge, p. 129-149.

Locke, T. 2004. Critical Discourse Analysis. London/New York: Continuum.

Magalhães, C.; Biavati, N. 2003. De operários, técnicos e executivos: representações do trabalhador em gênero do discurso midiático. Revista CROP, n. 9, p. 55-83.

MagalHÃEs, C. 2004. Interdiscursividade e conflito entre discursos sobre raça em reportagens brasileiras. Revista Linguagem em (Dis)curso, v. 4, n. especial, p. 35-60.

Matos, H. 1991. Legitimação do autoritarismo no Governo Médici: análise das primeiras páginas dos jornais $O$ Estado de São Paulo e $O$ Globo. Cadernos de Jornalismo e Editoração, São Paulo: s.n, v. 12, n. 27, p. 6179 , jan.

Mendes, I. S. M.; Magalhães, C. 2003. Um caso de polícia: a representação dos discursos no noticiário policial de dois jornais impressos brasileiros, abordada à luz da Linguística de Corpus e da Análise Crítica do Discurso. Dissertação de Mestrado. Belo Horizonte: UFMG.

Moura, C. 1988. Sociologia do negro brasileiro. São Paulo: Ática.

Pereira Jr., A. E. V.; Müller, K. M. 1998. Conotações ideológicas da expressão "acadêmico" na revista Veja. Áquila, Rio de Janeiro. v. 2, n. 3, jan./jun., p. 41-59.

Scotт, M. 2001. Comparing corpora and identifying key words, collocations, frequency distributions through the WordSmith Tools suite of computer programs. In: GHadesssy, M.; Roseberry, A. H. R. L. (Eds.) Small Corpus Studies and ELT: Theory and Practive. Amsterdam/Philadelphia: John Benjamins, p. 47-67. 
SiLva, V. G. 1994. Candomblé e umbanda: caminhos da devoção brasileira. São Paulo: Ática.

. 1999. Reafricanização e sincretismo: interpretações acadêmicas e experiências religiosas. In: Caroso, C.; Bacelar, J. (Orgs.). Faces da tradição afro-brasileira: religiosidade, sincretismo, antissincretismo, reafricanização, práticas terapêuticas, etnobotânica e comida. Rio Janeiro: Pallas, p. 149-157.

Sinclair, J. M. 1991. Corpus, Concordance, Collocation. Oxford: Oxford University Press.

Stubis, M. 1995. Collocations and semantic profiles: on the cause of the trouble with quantitative studies. Functions of Language, 2, 1:23-55. . 1996. Text and Corpus Analysis: Computer-Assisted Studies of Language and Culture. Oxford: Blackwell.

. 1997. Whorf's children: critical comments on critical discourse analysis (CDA). In: RYAN, A. \& WRAY, A. (Eds.). Evolving Models of Language. Clevedon: Multilingual Matters.

2001. Computer-assisted text and corpus analysis: lexical cohesion and communicative competence. In: Schiffrin D., TAnnen, D.; Hamilton H. E. (Eds.). The Handbook of Discourse Analysis. Oxford: Blackwell, p. 304-320.

. 2002. Words and Phrases: Corpus Studies of Lexical Semantics. Oxford: Blackwell.

Thompson, G. 1996. Introducing Functional Grammar. Oxford: Oxford University Press.

VAINFAS, R. 1995. A heresia dos índios: catolicismo e rebeldia no Brasil colonial. São Paulo: Companhia das Letras.

VAlente, V. 1976. Sincretismo religioso afro-brasileiro. 2. ed. São Paulo: Companhia Editora Nacional.

Williams, R. 1976. Keywords: A Vocabulary of Culture and Society. London: Fontana. 